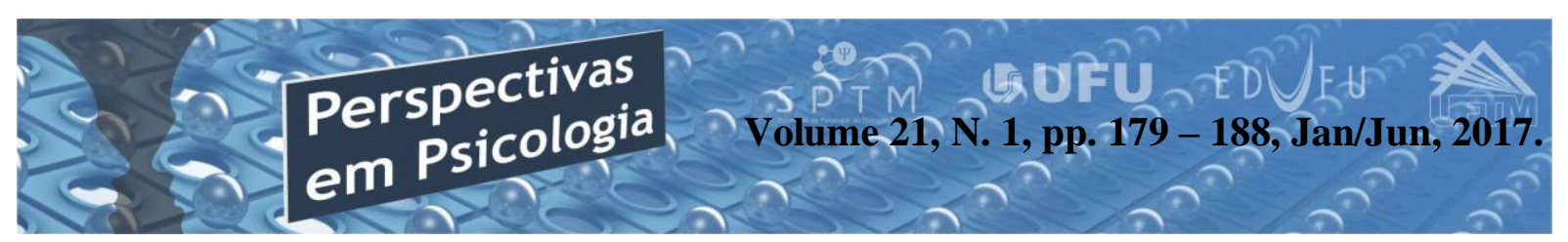

\title{
O DESENVOLVIMENTO DO PENSAMENTO DA CRIANÇA EM IDADE ESCOLAR: DO ABSTRATO AO CONCRETO
}

\author{
Noádia Munhoz Pereira \\ (Universidade Federal de Uberlândia - UFU)
}

\begin{abstract}
Resumo
$\mathrm{O}$ artigo analisa que, embora as crianças pequenas desenvolvam o pensamento teórico por meio da assimilação do conhecimento teórico, o aspecto genético é essencial para a operação desse mesmo pensamento, sendo assim, os estudos da teoria do ensino desenvolvimental, em específico, do sistema didático Elkonin-Davydov explora a hipótese do método geral para análise e solução de problemas escolares partindo de tarefas concretas, compreendendo a articulação entre o todo e as partes e vice-versa.Se expressa aqui conceitos sobre a tradição da teoria histórico-cultural fundamentada no materialismo histórico e dialético, visto que, desperta a orientação científica do pensamento dialético mental/abstrato e material/concreto da infância em atividade laboral.
\end{abstract}

Palavras-chave: Didática; desenvolvimento do pensamento; teoria histórico-cultural; infância.

\section{Abstract \\ The Development of Childhood Thinking at School Age from Abstract to Concrete}

The article analyzes that, although small children develop theoretical thinking through the assimilation of theoretical knowledge, the genetic aspect is essential for the operation of this same thought, and thus, studies of the theory of developmental teaching, in particular, of the didactic system Elkonin-Davydov explores the hypothesis of the general method for analyzing and solving school problems based on concrete tasks, including the articulation between the whole and the parts and vice versa. It expresses here concepts about the tradition of historical-cultural theory based on historical and dialectical materialism, since it awakens the scientific orientation of mental/abstract and material/concrete dialectic thinking of childhood in work activity.

Keywords: Didactics; thought development; historical-cultural theory; childhood.

Considerações Iniciais

A compreensão teórica da zona de desenvolvimento proximal no desenvolvimento do pensamento da criança é o que determina essencialmente as funções psicológicas superiores do pensamento na infância. $\mathrm{O}$ que metodologicamente o educador infantil 
traz ao observar a aprendizagem do aluno é de fundamental importância na condução dos meios e efeitos na assimilação a que se pretende nos primeiros anos escolares. As condições didáticas e a psicologia pedagógica se vinculam a alguns momentos de observação dos hábitos cultivados para cada criança, como por exemplo, ser capaz de sentar e adquirir a concentração em ouvir e após agir segundo a expectativa proposta pelo professor. Nesse contexto, cada criança demonstra níveis de experiência psíquicos na aprendizagem que podem ser satisfatórias para a idade de maturação a que se destina em seu convívio escolar. (Mello \& Campos 2013, p.273).

A matriz educativa referencial ao longo de muitos anos entende como tarefa principal e responsabilidade familiar o direcionamento da criança pequena particularmente com a mãe, após o desmame passa-se a ajudar os adultos nas atividades cotidianas iniciando-se assim, sua integração no meio social. Neste sentido, nos séculos XV e XVI os modelos educacionais da infância privilegiavam a criança pequena, como um pequeno adulto, era geralmente vistas como objeto divino, misterioso, de transformação pela direta imersão no ambiente doméstico. Com o advento do desenvolvimento científico, a expansão comercial e as atividades artísticas ocorridas no período do
Renascimento, estimularam o nascimento de novas visões sobre a criança e sobre como ela deveria ser educada, isto é, Erasmo (1465-1530) e Montaigne (14831553), sustentavam que a educação deveria respeitar a natureza infantil, estimular a atividade da criança e associar o jogo à aprendizagem. (Oliveira, 2007, p.59)

Esses dois pioneiros acreditavam que gradativamente a sociedade vira-se impelida a elaborar arranjos formais para atendimento de crianças vitimizadas socialmente pela Revolução Industrial, vítimas da pobreza, abandono e maustratos. As instituições à princípio de caráter filantrópico tinham uma proposta instrucional formal, de exploração as atividades de canto, de memorização de rezas ou passagens bíblicas e alguns exercícios do que poderia ser uma préescrita ou pré-leitura. Tais atividades, voltam-se para o desenvolvimento de bons hábitos de comportamento, a internalização de regras morais e de valores religiosos, além da promoção de rudimentos de instrução. A leitura e a escrita ensinadas a partir dos 6 anos objetivavam o ensino em sua religiosidade, o que caracterizou por sua vez, as primeiras iniciativas educacionais nos jardins da infância.

Além disso, por outro lado, o desenvolvimento científico mobilizou o pragmatismo tecnicista, o que por sua vez, gerou condições e um terreno fértil para a 
formulação de um pensamento pedagógico modernizante. A questão do 'como ensinar', adquiriu proporção significativa para a educação das crianças pequenas por meio das idéias dos precursores da teoria de Comênio (1592-1670), Rousseau (17121778), Pestalozzi (1746-1827), Decroly (1871-1932), Froebel (1782-1852) e Montessori, dentre outros, que estabeleceram as bases para um sistema de ensino mais centrado na criança, com o interesse pela exploração de objetos e pelo contato com o jogo.

A seguir desenvolver-se-á reflexões teóricas respaldadas pela teoria históricocultural, disponibilizadas pelas inspirações da pedagogia moderna educacional, organizada para a exploração pedagógica dos sentidos e da percepção da criança pequena ao nível de desenvolvimento laboral integrado a percepção sensóriomotora e suas condições favoráveis de aprendizado. A dimensão pedagógica explicita as condições psíquicas favoráveis para o desenvolvimento do pensamento e as condições psicomotoras favoráveis para a exploração do ambiente físico.

\section{Fundamentos histórico-culturais do pensamento da criança}

Parte-se do pressuposto teórico vygotskiano de que a aprendizagem é uma articulação constante entre processos internos e externos, que possuem o objetivo de que a criança internalize os signos culturais que exercem ação reguladora do comportamento e de funções mentais superiores outrora relacionados com o caráter de mediação sociocultural da aprendizagem. A interação no ambiente de aprendizagem com saberes e instrumentos de desenvolvimento mental oportunizam as condições internas de assimilação e cognição dos saberes.

Cabe ressaltar que o suporte da teoria histórico-cultural da aprendizagem consiste em relacionar as competências sociais como fator preponderante para incentivar a aprendizagem de maneira mais significativa para a criança. Para que a criança aprenda é preciso estimular procedimentos essenciais do pensamento e assim, proceder metodologicamente para a inclusão de novos conteúdos diante dos já abstraídos pelo pensamento em seu primeiro nível cognitivo de aprendizagem.

O que está em questão é como o ensino pode impulsionar o desenvolvimento das competências cognitivas mediante a formação de conceitos e desenvolvimento do pensamento teórico, e por quais meios os alunos podem melhorar e potencializar sua aprendizagem. Em outras palavras, trata de saber o que e 
como fazer para estimular as capacidades investigadoras dos alunos, ajudando-os a desenvolver competências e habilidades mentais. Em razão disso, uma didática a serviço de uma pedagogia voltada para a formação de sujeitos pensantes e críticos e deverá salientar em suas investigações as estratégias pelas quais os alunos aprendem a internalizar os conceitos, competências e habilidades do pensar, modos de ação que se constituam em " instrumentalidades" para lidar praticamente com a realidade: resolver problemas, enfrentar dilemas, formular estratégias de ação. (Libâneo, 2004, p.27-28)

O pensamento subjaz ao modo de ação e sua aplicabilidade dialógica na atividade de estudo, ou seja, a criança quando influenciada pelas circunstâncias concretas da vida, muda o lugar que ocupa objetivamente nas relações humanas. Os conhecimentos prévios, trazidos pela criança não são totalmente necessários na mediação do conhecimento, mas sim os signos, os instrumentos da aprendizagem, como por exemplo, a linguagem. Sendo assim, os instrumentos da linguagem utilizam-se dos signos para trazer a dialogicidade para a comunicação entre os sujeitos. No movimento de se interiorizar o problema está no caráter definidor, no caráter gerador/definidor da psiquê. Devemos atribuir ao sujeito o potencial de aprender influenciado pela realidade mais próxima de algo que ele produz, esse seria o papel fundamental da didática no processo de ensino e aprendizagem.

A percepção do pensamento dotada de orientação determinada vê a investigação da atividade mental enquanto uma estrutura num dado plano de ação segundo as ações do mundo exterior, ou seja, é através do conhecimento da essência dos fenômenos naturais que a ação material do homem/sujeito sobre os objetos conduz a sua transformação e a sua posterior atividade criativa, daí então, que a investigação da atividade mental estar relacionada com o pensamento abstrato mediante sua ação sobre os objetos percebidos. Assim, os principais princípios do sistema didático experimental se ocupam das seguintes formulações metodológicas para o processo de ensino aprendizagem, quais sejam: a) $\mathrm{O}$ ensino a um alto grau de dificuldade; b) Enfatizar o conhecimento de conceitos teórico; c) Manter um ritmo acelerado no cumprimento do conteúdo curricular; d) Provocar o aluno a consciência da autoaprendizagem e e) Planejar com cuidado as aulas para promover a aprendizagem a cada aluno em particular. 
Primeiro os alunos devem aprender o aspecto genético e essencial dos objetos, ligado ao modo próprio de operar da ciência, como um método geral para análise e solução de problemas envolvendo tais objetos. Depois, utilizando o método geral, os alunos resolvem tarefas concretas, compreendendo a articulação entre o todo e as partes e vice-versa. A este procedimento mental Davydov denominou de pensamento teórico. (Libâneo \& Freitas, 2013, p.320)

As teses em que se baseou o sistema de ensino de Davydov ${ }^{1}$, incorporou os fundamentos teóricos de Vygotsky de que o aprendizado não é, em si mesmo, desenvolvimento, mas, se organizado corretamente, ativa processos de desenvolvimento mental na criança que seriam impossíveis fora do processo de aprendizado. Como Vygotsky, Davydov também compreende o aprendizado como intrinsecamente necessário e universal ao desenvolvimento das características humanas que não são dadas pela natureza biológica e sim formadas historicamente.

\footnotetext{
${ }^{1}$ Seus estudos não apenas aprimoraram a teoria pedagógica dentro da teoria histórico-cultural como levou a consequências práticas a relação entre educação e desenvolvimento formulado por Vygotsky.
}

Já Elkonin ${ }^{2}$, dedicou-se ao estudo da brincadeira infantil em seu papel de desenvolvimento psíquico na criança, o seu foco investigativo, estruturou a periodização do desenvolvimento psíquico, considerando-a fundamental para a psicologia infantil, na medida em que se definem as forças motrizes e as leis do trânsito de um período ao outro no desenvolvimento da infância. (Lazaretti, 2013, p.209).

Ambos teóricos projetaram o processo de ensino e aprendizagem em sua relação de que as condições sociais objetivas não devem passar despercebidas e consequentemente interfere no psiquismo na medida em que a criança vai se desenvolvendo. Assim, no primeiro ano de vida, a criança aprende somente a utilizar as propriedades externas dos objetos, ou seja, da mesma forma que manipula o lápis, manipula também a colher ou um pau, visto que, a passagem para a primeira infância engendra nova forma de atitude frente ao mundo dos objetos, o uso social dos objetos domina os procedimentos e cumprem uma tarefa de experiência social

\footnotetext{
${ }^{2}$ Debruçou boa parte de sua carreira científica ao estudo sobre a brincadeira infantil, iniciou na década de 1930 e em 1948, publica em parceria com os colegas Frádkina, Vartchavskaia, Guerchenon, Konnokova, Lukóv e Slávia o primeiro texto intitulado Questões Psicológicas da Brincadeira em Idade Pré-escolar, no qual são apresentados os primeiros resultados de sua investigação, esse estudo se concluiu em 1978 com a publicação do libro a Psicologia do Jogo.
} 
para a criança em fase de desenvolvimento de sua psicomotricidade. A partir dos três anos surgem novas atividades e um novo tipo de ações com os objetos, haja vista, que começa a se determinar o desenvolvimento psíquico das formas produtivas da sua ação, como por exemplo, na criação do desenho, da modelagem com argila,da construção de blocos lógicos, dentre outras situações de aprendizagem.

No entanto, na primeira infância, Elkonin, postula que na ação objetal a criança se inclui no sistema das relações humanas e se descobre nessa ação. $\mathrm{O}$ verdadeiro sentido social de sua orientação para com as outras pessoas, tal inclusão só e apenas, têm lugar mediante a brincadeira, a aspiração da criança pequena em sua preparação para a aprendizagem consiste na importância básica da brincadeira, para o seu desenvolvimento psíquico, nisso consiste sua função dominante. Nessa mesma direção, no decorrer da idade escolar, a passagem da infância à adolescência é caracterizada como um período de atividade comunicacional, com alterações nas premissas da responsabilidade, do compromisso e da coletividade, pois se estabelecem interesses profissionais, portanto, a atividade profissional de estudo torna-se dominantes, desempenhando um importante papel na formação o ensino politécnico, ao serem transmitidos os conhecimento teóricos, que são a base da produção e da prática profissional.

Por meio da brincadeira, a criança pequena exercita capacidades nascentes, como as de representar o mundo e de distinguir entre pessoas, possibilitadas especialmente pelos jogos de faz-de-conta e os de alternância, respectivamente. Ao brincar, a criança passa a compreender as características dos objetos, seu funcionamento, os elementos da natureza e os acontecimentos sociais. Ao mesmo tempo, ao tomar o papel do outro na brincadeira, começa a perceber as diferentes perspectivas de uma situação, o que the facilita a elaboração do diálogo interior característico de seu pensamento verbal (Oliveira, 2007; p. 160)

O desenvolvimento intelectual em idade escolar possibilita a criança interpretar o mundo de diversas formas, de modo que, a teoria vygotskiana considera como ponto de partida que a aprendizagem da criança começa muito antes da aprendizagem escolar, assim, a aprendizagem deve ser coerente com o nível de desenvolvimento, estímulos emocionais e visuais disponibilizados no ambiente escolar, que é denominado de desenvolvimento potencial, o qual a 
criança adquire sem a interferência do adulto. (Vigotsky, 2010, p.115)

Desta maneira, a teoria históricocultural da atividade está amparada pelo determinismo do pensamento psicológico, pelo idealismo pragmático e pelo positivismo, já a teoria histórico-cultural da subjetividade está amparada pela dialética do pensamento psicológico e não há uma relação de causa efeito. São dois os fenômenos que se inter-relacionam com objetivo de produção, assimilação e reprodução ao internalizar conceitualmente como fora da realidade a criação do pensamento e da atividade mental, portanto, configura-se como um ato de produção e assimilação do sujeito social. Assim, a internalização e a interiorização do conhecimento são diferentes, pois, tradicionalmente se memoriza o conceito já subjetivamente criado em si, o que por sua vez, se se constitui um projeto científico mediante uma nova etapa de memorização. $\mathrm{Na}$ teoria da subjetividade não há uma transferência de conhecimento, mas sim, a valorização do seu eu interno.

O pré-condicionamento social induzido pela Psicologia histórico-cultural da atividade introduz certa ditadura social e certa fragmentação no processo de ensino aprendizagem pressupondo que o aluno não abstrai o conteúdo apenas copia e memoriza, desta maneira, não se valoriza a construção do pensamento cognitivo e emocional. Entretanto, é preciso atentar para o sistema de internalização das funções cognitivas e não se esmerar pela generalização do conceito da consciência, ou até mesmo, de um sujeito alienado e estranhado em suas funções cognitivas. Defende-se um sistema de unidades diferentes de generalizações pragmáticas. (Puentes \& Longarezi, 2013, p.249)

Contudo, a escola é responsável por conduzir na criança pequena $o$ desenvolvimento do pensamento teórico que favorece neste momento em especial, a sua percepção e a sua memorização dos principais conceitos, assim, segundo Davydov, pensar significa inventar, construir na mente o projeto ideal (o que corresponde as finalidades da atividade em sua idéia primeira) do objeto real que deve ser o resultado do processo laboral colocado em pressuposto, daí ao pensamento teórico são atribuídas algumas particularidades específicas, tais como: a) o objeto do conhecimento é colocado mentalmente em condições de objetividade; b) a realidade se modifica em objeto das posteriores transformações mentais; 3) no experimento dado se forma um sistema de conexões mentais dentro do qual é situado o objeto. (Puentes \& Longarezi, 2013, p. 256). 
A partir dessa concepção o desenvolvimento do pensamento da criança em idade escolar pressupõe a identificação das necessidades e a criação das necessidades comuns em seus motivos fazendo coincidir a movimentação das ações em torno do direcionamento de atividades de estudo no desencadeamento de situações formativas de transformação das capacidades e habilidades mentais da criança. A exemplo as situações imaginativas das experiências escolares com as brincadeiras de crianças em pequenos grupos possibilita na maioria das vezes a criação de enredos de faz-de-conta que promovem no espaço educativo elementos de riqueza conceitual na construção de novos significados para a aprendizagem.

A concretização de propostas pedagógicas que visa à organização do trabalho pedagógico na construção de um percurso projectual que saia da fragmentação de esforços para a criação de um trabalho interdisciplinar, cooperativo e lúdico. A vulnerabilidade da infância consiste em repensar a maneira mais articulada possível, com a introdução de novas descobertas em sua complexidade subjetiva. "A pedagogia de projetos vê a criança como um ser capaz, competente, com um imenso potencial e desejo de crescer. Alguém que se interessa, pensa, duvida, procura soluções, tenta outra vez, quer compreender o mundo a sua volta e participar [...]". (Barbosa \& Horn, 2008, p. 87).

\section{Considerações Finais}

De acordo com o decorrer das análises problematizadas acima em relação à atividade de estudo e a relação da criança com o ambiente externo, as proposições baseadas na lógica e na psicologia, as quais podem ser utilizadas na seleção do conteúdo das matérias pedagógicas, levando em consideração a ascensão do pensamento do abstrato ao concreto; temos as seguintes preposições sobre o que a criança seria capaz de abstrair de acordo com as particularidades exigidas a se conhecer e metas cognitivas a serem alcançadas. Vejamos:

a) $\mathrm{A}$ assimilação dos conhecimentos de natureza geral e abstrata precede o conhecimento pelas crianças de temas mais particulares e concretos; estes últimos são deduzidos pelos próprios alunos a partir do geral e abstrato, como única base que formam;

b) As crianças pequenas assimilam os conhecimentos que constituem um conteúdo particular ou suas partes básicas, no processo de análise das condições sob as quais é originado e que os tornam essenciais; 
c) Ao serem verificadas as fontes objetais de alguns conhecimentos, os alunos devem, antes de tudo, saber como identificar no material de estudo a relação geneticamente inicial, essencial e universal, que determina o conteúdo e a estrutura do objeto destes conhecimentos;

d) As crianças reproduzem esta relação em específicos modelos objetais, gráficos ou de letras, que lhes permitem estudar suas propriedades em sua forma pura;

e) As crianças devem ser capazes de concretizar a relação geneticamente inicial e universal do objeto em estudo em um sistema de conhecimentos particulares sobre ele, os quais devem manter-se em uma só unidade, que possa garantir as transições mentais do universal para o particular e vice-versa;

f) As crianças devem saber passar da realização das ações no plano mental à sua realização no plano externo e viceversa.

O conteúdo concreto de uma matéria escolar está correlacionado à forma da consciência social que esta matéria representa (por este motivo, o conteúdo é definido por um especialista da matéria). As proposições enunciadas acima destacam certos aspectos lógicos e psicológicos das habilidades fundamentais que devem ser formadas nos escolares durante a assimilação de uma matéria escolar. À medida que um programa de uma matéria inclui tanto habilidades como conhecimentos, as habilidades mencionadas devem também ser incluídas nele.

Portanto, o sistema didático Elkonin-Davydov elabora diretrizes válidas para a compreensão das etapas de assimilação do conhecimento respeitando os aspectos cognitivos, sociais e emocionais da criança, assim como, explorando a imaginação e diferentes linguagens o processo de ensino aprendizagem da criança pequena em idade escolar.

\section{Referencias}

Barbosa, M. C.S. \& Horn, M. G.S. (2008) Projetos pedagógicos na educação infantil. Porto Alegre: Artmed.

Davydov, V.V. (1998). Problemas do ensino desenvolvimental: a experiência da pesquisa teórica e experimental na Psicologia. In: Revista Soviet Education, August/Vol XXX, $\mathrm{N}^{\circ}$ 
8, Davídov, V. V. La enseñanza escolar y el desarrollo psíquico. Moscú: Editorial Progreso.

Kishimoto, T. M. (Org). (1998). O brincar e suas teorias. São Paulo: Pioneira.

Lazaretti, L. M. Daniil Borisovich Elkonin: a vida e as produções de um estudioso do desenvolvimento humano. (2013) In: Longarezi, A. M. \& Puentes, R. V (Orgs). Ensino desenvolvimental: vida, pensamento e obra dos principais representantes russos. (p.203231). Uberlândia: EDUFU.

Libâneo, J. C. (2004). A didática e a aprendizagem do pensar e do aprender: a teoria históricocultural da atividade e a contribuição de Vasili Davydov. In: Revista Brasileira de Educação. №27. Set/out. https://doi.org/10.1590/s1413-24782004000300002.

Libâneo, J. C. \& Freitas, R., A. M. (2013). Vasilyevich Davidovy: escola e a formação do pensamento teórico-científico. Longarezi, A. M. \& Puentes, R. V (Orgs). Ensino desenvolvimental: vida, pensamento e obra dos principais representantes russos. (pp.327-362), Uberlândia: EDUFU.

Oliveira, Z, R. (2007). Educação infantil: fundamentos e métodos. São Paulo. Cortez. (Coleção Docência em Formação).

Mello, M. A. \& Campos, D. A. (2013). Bases conceituais da obra de A. V. Petrovsky: implicações nos processos de ensinar e aprender na escola. In: Longarezi, A. M. \& Puentes, R. V (Orgs). Ensino desenvolvimental: vida, pensamento e obra dos principais representantes russos. (pp.263-281), Uberlândia: EDUFU.

Puentes, R. V. \& Longarezi, A. M.(2013). A didática desenvolvimental: seu campo conceitual na tradição da psicologia histórico-cultural da atividade. Educação em Revista, 29(1), p. $241-271$.

Vigotski, L. S. (2010). Linguagem, desenvolvimento e aprendizagem. São Paulo: Ícone.

A autora:

Noádia Munhoz Pereira é licenciada em Pedagogia, mestre em educação pela Universidade Federal de Uberlândia e doutoranda no Programa de Pós-Graduação em Educação na Universidade Federal de Uberlândia. E.mail: noadia.pereira@ufu.br

Recebido em: 13/06/2017

Ajustes em: 20/06/2017

Aprovado em: 29/06/2017 